\title{
Turismo, producción inmobiliaria y procesos espaciales: la difusión del modelo turístico espańol hacia Brasil
}

María-Aparecida Pontes. Universidad Federal de Rio Grande do Norte, Natal, Brasil. Ramón García-Marín. Universidad de Murcia, Murcia, España.

Daniel Moreno-Muñoz. Universidad de Murcia, Murcia, España.

RESUMEN | En las últimas décadas se ha implementado en el litoral mediterráneo español un modelo turístico basado en la construcción de complejos residenciales próximos a la costa, la mayoría de ellos asociados a un campo de golf, con viviendas adquiridas en general por ciudadanos de otros países europeos. Este proceso (19952007) ha generado un vigoroso mercado inmobiliario y diversos fenómenos socioespaciales, como gentrificación, segregación, homogeneización o fragmentación del espacio urbanizado, en un modelo que ha sido exportado a diversos lugares, como el continente americano. El objetivo de la presente investigación es analizar la difusión del modelo turístico español hacia Brasil, concretamente su presencia en Polo Costa das Dunas, en el Estado de Rio Grande do Norte. Esta transmisión se debe principalmente a las empresas constructoras de capital europeo que invierten en el citado territorio. La conclusión más relevante es la difusión y traslado, a otras realidades, de los procesos socioespaciales urbanos que caracterizan el modelo turístico residencial español.

PALABRAS CLAVE | mercado inmobiliario, transformaciones socioterritoriales, geografía urbana.

ABSTRACT | In recent decades, a tourist model based on the construction of residential complexes close to the coast has been implemented on the Spanish Mediterranean coast, with homes generally acquired by citizens of other European countries. This process has generated a vigorous real estate market (1995-2007) and various socio-spatial phenomena, such as gentrification, segregation, homogenization or fragmentation of the urbanized space, in a model that has been exported to various places, such as the American continent. The objective of the present investigation is to analyze the diffusion of the Spanish tourist model towards Brazil, specifically its presence in Polo Costa das Dunas, in the State of Rio Grande do Norte. This transmission is mainly due to the European capital construction companies that invest in the aforementioned territory. The most relevant conclusion is the dissemination and transfer of the urban socio-spatial processes that characterize the Spanish residential tourism model.

KEYWORDS | real-estate market, socio-territorial transformations, urban geography. 


\section{Introducción}

La vinculación entre turismo y mercado inmobiliario ha llegado a ser en las últimas décadas una realidad evidente. En este proceso, el paradigma del turismo de masas desarrollado en la posguerra constituye un factor central en la promoción del mercado inmobiliario en el Mediterráneo español (Martínez-Medina, 2016; Mazón, 2016). La asociación entre turismo y dinámica inmobiliaria ha ido asumiendo cada vez mayor relevancia, originando grandes y complejas urbanizaciones con fines turísticos a lo largo del litoral y en áreas interiores próximas a este (Moreno, 2007). A comienzos de la presente centuria, el modelo de urbanización turística de Espańa se difundió hacia otros países y continentes, como el Norte de África, América Central, Caribe y Brasil (Aledo, 2016). En este último caso, el Nordeste brasileño recibió inversiones procedentes de Europa (portuguesas, espańolas y noruegas) que introdujeron nuevas tipologías y cánones urbanísticos, inexistentes hasta entonces en la costa nordestina (Silva, 2010; Silva \& Ferreira, 2012). La llegada de los nuevos agentes inmobiliarios con aportes de capital aceleró la inserción del litoral nordestino en el mercado inmobiliario globalizado y la intensificación del proceso urbanístico a lo largo de la zona costera.

Existe una cantidad significativa de estudios sobre la burbuja inmobiliaria asociada al turismo. No obstante, no se observan trabajos que indaguen suficientemente en la naturaleza del espacio urbano producido con la expansión del turismo y sus actividades relacionadas, particularmente la actividad inmobiliaria. La propuesta del artículo es contribuir en esta línea de investigación a partir del análisis de la difusión del modelo turístico ibérico en el Nordeste brasileño, buscando identificar los procesos espaciales urbanos resultantes de la expansión del turismo en las áreas litorales.

En la primera parte del texto se realiza una breve síntesis de los trabajos que discuten la urbanización turística, su naturaleza y características. Posteriormente se reflexiona sobre el proceso de urbanización a partir de la relación entre turismo y mercado inmobiliario, teniendo como base empírica la Costa Cálida (Sureste de España) y el Polo Costa das Dunas (Nordeste de Brasil), áreas turísticas cuyo principal reclamo turístico es el sol y la playa, asociado en el caso espańol a los campos de golf. Por último, se examinan los principales procesos espaciales urbanos identificados en las áreas de estudio y que han surgido sea como producto de este modelo de urbanización turística, o asociados a él.

\section{Metodología}

Para la elaboración del presente estudio se realizó, en primer lugar, una revisión bibliográfica exhaustiva del tema en cuestión. Seguidamente, se recopiló información acerca de las inversiones internacionales en el segmento inmobiliario en Polo Costa das Dunas, concretamente para seis municipios ubicados en la zona norte del territorio: Extremoz, Ceará Mirim, Maxaranguape, Rio do Fogo, Touros y São 
Miguel do Gostoso. El tratamiento de datos comprendió el periodo 2000-2013, ${ }^{1}$ en cuyo marco se reflexionó sobre las informaciones derivadas de las inversiones y transacciones de inmuebles que involucran a extranjeros, sea como compradores, o como vendedores para otro foráneo o para brasileños. Esta zona fue seleccionada por el hecho de haberse incorporado al mercado inmobiliario justamente en este periodo de llegada de las inversiones extranjeras en el sector de la construcción.

Por último, se efectuó un trabajo de campo con el fin de comprobar in situ cómo han surgido procesos espaciales asociados a la construcción de urbanizaciones residenciales en el Nordeste brasileño similares a los de la Costa Cálida (España) y qué repercusiones tienen en los citados territorios.

\section{Área de estudio}

Para el desarrollo de esta investigación se han escogido dos áreas, la Costa Cálida (España) y Polo Costa das Dunas (Brasil), ya que guardan similares características o condicionantes para el desarrollo del turismo residencial (tabla 1).

Características climáticas: Poseen un clima bonancible a lo largo de todo el año, con temperaturas medias que superan los $20^{\circ} \mathrm{C}$.

Precios: Los terrenos donde se edificaron las urbanizaciones fueron adquiridos por los promotores con un coste muy bajo. Por su parte, las viviendas construidas se vendieron a un precio elevado.

Destinatarios: Los inmuebles son adquiridos en su gran mayoría por ciudadanos extranjeros jubilados con mayores rentas económicas que los de la comunidad receptora.

Ambiente social: Se han generado comunidades de compatriotas y existe una gran hospitalidad por parte de la población receptora. No obstante, suelen formarse guetos según la nacionalidad.

Calidad de vida: Además del clima, en estas urbanizaciones existe una seguridad privada, a la par de servicios como bares, restaurantes, piscinas o gimnasios. Sin embargo, muchos complejos residenciales carecen de servicios sanitarios.

Comunicaciones: Para el impulso de este tipo de turismo, ambos lugares han fomentado la construcción de infraestructuras que garanticen una buena accesibilidad al territorio.

TABla I | Variables similares entre la Costa Cálida y Polo Costa das Dunas para el impulso del turismo residencial

FUENTE: ELABORACIÓN PROPIA

Brasil y España son dos países con tradición turística litoral, ya que ambos cuentan con zonas costeras caracterizadas por una bonanza climática a lo largo de todo el año que atrae a numerosos turistas (Ponce \& Espejo, 2009; Pontes, Santos \& Nunes, 2016). No obstante, si se realiza una comparación a escala internacional entre los principales receptores de turismo de sol y playa internacional, Brasil aparece como una nación emergente con enorme potencial, mientras Espańa se muestra como un destino maduro (Soares, Ivars \& Gândara, 2015).

En España y en Brasil se ha producido en las últimas décadas un proceso de urbanización litoral motivado por las prácticas de ocio y turismo, y relacionado con la expansión del segmento inmobiliario en la producción de segundas residencias. Este

1 En el municipio de Extremoz, la recogida de datos comprendió el período 2000-2010, debido a dificultades para su obtención. 
hecho se ha verificado en regiones como la Costa Cálida o la Costa Blanca, en el caso español, y en el Nordeste y Sudeste brasileños, con la construcción intensiva de urbanizaciones cerradas destinadas a segundas residencias para fines turísticos y de ocio.

La Costa Cálida, ubicada en la Región de Murcia (España) (figura 1), ha centrado tradicionalmente su oferta turística en el modelo de sol y playa (Huete \& Mantecón, 2011; Salvá, 1998). Recientemente, con la saturación constructiva del litoral, el fenómeno de la urbanización turística se ha trasladado a áreas interiores, donde se han desarrollado nuevos resorts con campos de golf, que han devenido una de las principales atracciones turísticas (Vera \& Espejo, 2006). Esto provoca la paradoja, de acuerdo con Espejo y Cànoves (2011), de que en una región con un déficit hídrico importante exista un número elevado de campos de golf, incrementándose con ello la demanda de agua. Conviene recordar que este desarrollo es favorecido por las condiciones climáticas, la proximidad al mar y la presencia del eje territorial mediterráneo, todos factores atractivos para una demanda procedente, principalmente, del Reino Unido y Alemania.
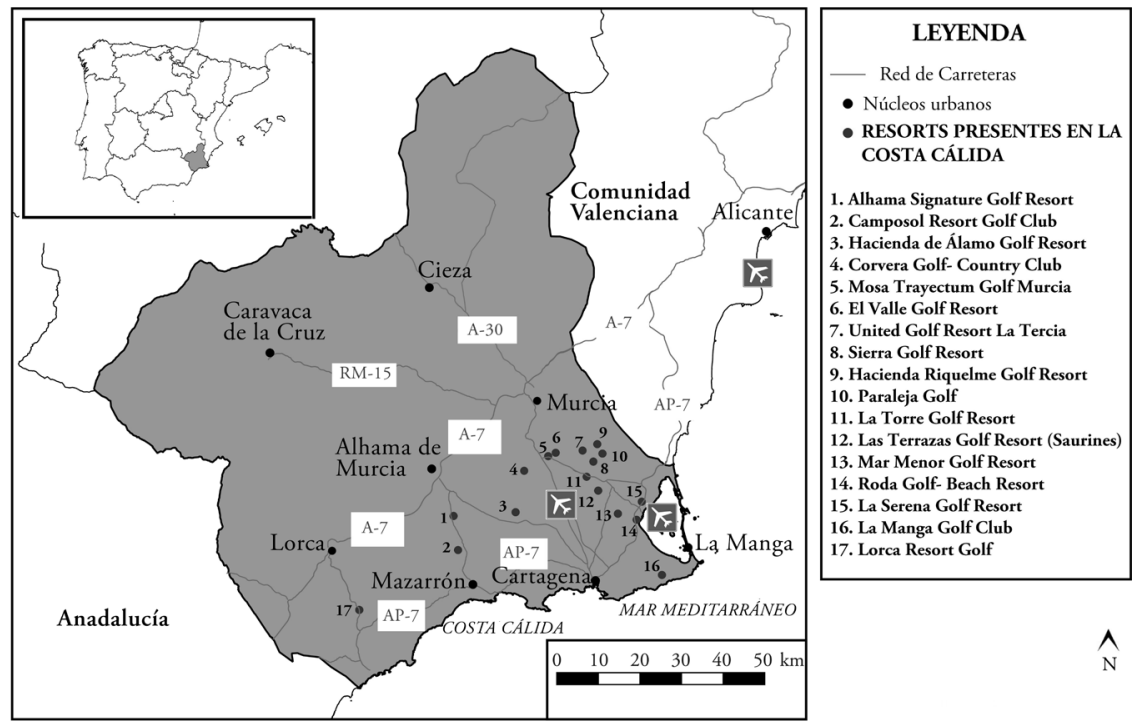

Figura I | Costa Cálida (Región de Murcia). Localización de resorts asociados a campos de golf

FUENTE: ELABORACIÓN PROPIA

Polo Costa das Dunas se localiza en el litoral oriental brasileño (figura 2) y se constituye como el principal destino turístico del Estado de Rio Grande do Norte. El desarrollo turístico proliferó a partir de 1990, coincidiendo con la estabilidad económica del país (Cruz, 2009). El comienzo del siglo actual señala la internacionalización del turismo, con la llegada de flujos, inversiones hoteleras e inmobiliarias para la construcción de viviendas secundarias procedentes del exterior, sobre todo de países mediterráneos -Portugal y Espańa, principalmente- y escandinavos (Assis, 2009). 
Factores como la longitud de la costa y su calidad visual, un clima bonancible exento de catástrofes naturales, inversiones en infraestructuras, ser el punto de América más próximo a Europa, o los bajos precios del coste de la vida, motivaron la llegada de turistas procedentes de Europa, especialmente de Noruega (Assis, 2009). Es decir, los factores que propician la atracción de turistas e inversiones extranjeras en Polo Costa das Dunas se asemejan a los existentes en la Costa Cálida.

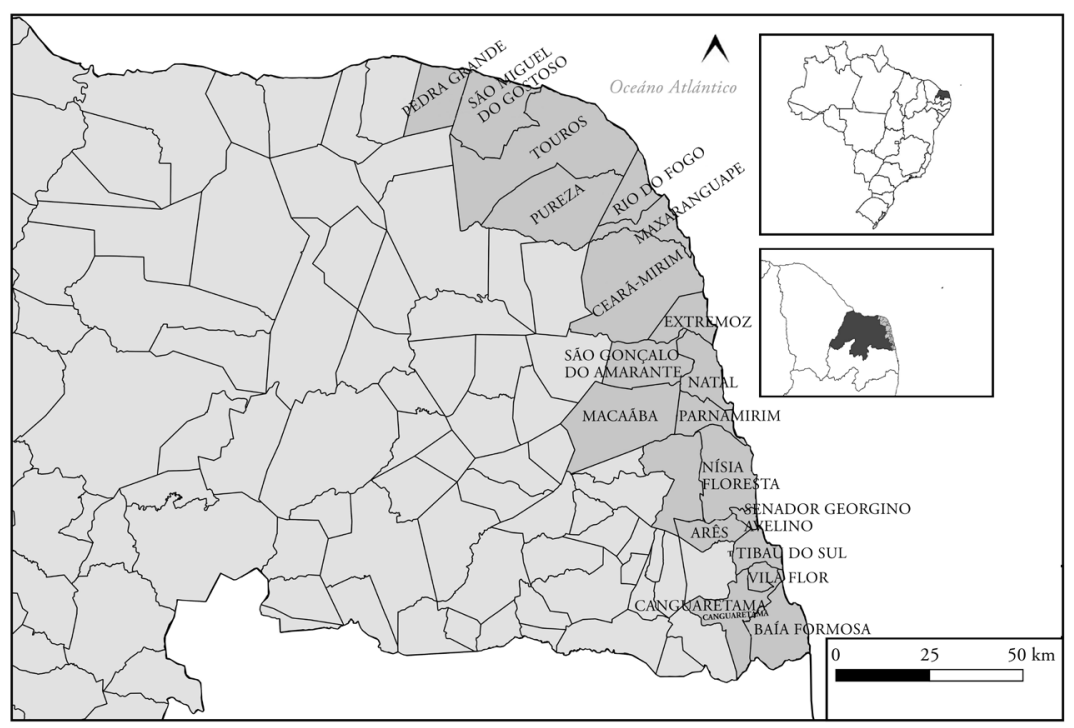

FIgura 2 | Localización Polo Costa das Dunas / Rio Grande do Norte (Brasil) FUENTE: GRUPO INTERDISCIPLINAR SOCIEDADE E TURISMO, UNIVERSIDADE FEDERAL DO RIO GRANDE DO NORTE (UFRN)

\section{Marco teórico: la difusión del turismo y el proceso de urbanización}

El capitalismo basado en la producción industrial generó un intenso proceso de urbanización. Muchos estudios revelan que los dos procesos (industrialización y urbanización) estaban intrínsecamente relacionados. En la última fase del capitalismo se verifica la enorme expansión de la urbanización y, particularmente, un proceso en que la actividad turística potencia de forma muy significativa la expansión urbana y la redefinición de áreas urbanas preexistentes, ya sea en su función, forma o significado. Es decir, industria, turismo y urbanización están íntimamente ligados.

Mullins (1991) afirma que mientras la urbanización oriunda de la producción industrial tenía como fundamento la producción y el trabajo, la urbanización originada por el turismo se fundamenta en el consumo para ocio, diversión y descanso. Como la edificación turística es realizada para el consumo de los turistas, según este autor no hay necesidad de ofertar algunos servicios básicos como salud y educación, destinados especialmente a la población residente. Cabrerizo (2016) también observa que en las ciudades que asumen la función turística existen muchos lugares para el consumo, ya sea de bienes materiales o de experiencias, tanto públicos como 
privados. Por su parte, Paiva y Vargas (2013) observan que el análisis de Mullins en 1991 se limita al proceso de urbanización generado exclusivamente por el proceso de producción y consumo del espacio para el turismo, y que deja de lado el consumo turístico de otras ciudades tradicionales ya consolidadas, pues en muchos casos se comprueba la coexistencia del turismo con otras prácticas socioespaciales en los procesos de urbanización.

$\mathrm{Si}$, por un lado, la actividad turística produce espacio urbano, por otro se alimenta de su consumo (Brito, 2003). Desde los inicios de esta actividad, las grandes ciudades europeas se consolidaron como importantes destinos turísticos, lugares visitados particularmente por la aristocracia inglesa (Boyer, 2003; Rejowski, 2002). Los puntos de referencia de la ciudad (edificios o monumentos), que generalmente revelan períodos de esplendor, así como formas modernas y contemporáneas existentes, han devenido objetos de interés turístico (Silva, 2004). Además de esto, es necesario resaltar que las grandes ciudades son las principales emisoras de turistas y tienen una participación fundamental en la distribución de flujos turísticos, una vez que se constituyen en importantes nodos de conexión en las redes urbanas (Paiva \& Vargas, 2013).

Sin duda, la enorme expansión de la actividad turística potenció y dirigió la producción inmobiliaria destinada a las segundas residencias, particularmente en áreas costeras. Como resultado, existe una urbanización rectilínea a lo largo de las áreas turísticas litorales y prelitorales, en la medida en que acontece la saturación de la primera línea de playa.

La producción de inmuebles destinados a segundas residencias aumenta a partir de la década de 1970, justamente cuando ocurre la crisis del modelo de producción fordista, basado en la producción de bienes de consumo materiales. Lefebvre (1972) y Harvey $(1980,2005)$ realizan valiosas contribuciones a la comprensión de la relevancia lograda por el sector inmobiliario a partir de este periodo. Observan al respecto que en la medida en que la producción de bienes que caracterizó el régimen de acumulación fordista deja de ser rentable, parte del capital migra desde el sector industrial al inmobiliario. Así, el circuito secundario (especulación y construcción) ha asumido el papel del circuito primario (industrial) en la acumulación del capital.

Analizando la dinámica espacial del capital en la evolución del capitalismo, Harvey (2011) observa que el capital excedente está siempre a la búsqueda de nuevas posibilidades de valorización y nuevos espacios que proporcionen beneficios extraordinarios. En esta perspectiva es posible comprender la difusión de las inversiones turísticas-inmobiliarias en el Mediterráneo occidental y posteriormente su transfusión hacia el Nordeste brasileño. El capital disponible encontró en estas regiones nuevas oportunidades para realizar negocios lucrativos que proporcionaban grandes rentas.

Harvey (2011) ofrece pistas importantes para comprender la expansión del fenómeno de segundas residencias, cuando afirma que la producción urbana vinculada al sector inmobiliario ha sido estratégica para viabilizar nuevas inversiones. En palabras del autor: 
La construcción de espacios, como la creación de una vivienda segura llamada casa u hogar, tiene un impacto en la tierra en cuanto la acumulación del capital y la producción de tales lugares se vuelve un gran vehículo para la producción y absorción del excedente. La producción de lo "urbano", donde la mayoría de la población mundial en crecimiento ahora vive, se volvió a lo largo del tiempo estrechamente ligada a la acumulación de capital, hasta el punto en que es difícil distinguir una de la otra. (p. 122)

La explicación elaborada por Harvey, en que asocia la producción del espacio urbano a la valorización de capitales excedentes y a la reproducción de capital, posibilita entender la enorme expansión de segundas residencias en localidades turísticas durante las últimas décadas. Así, la producción de espacio urbano generado por el consumo turístico y la práctica de ocio (segundas residencias) ha sido una de las formas de viabilizar nuevas inversiones inmobiliarias y contribuir a la absorción de capitales disponibles en el mercado, que encuentra en este segmento inmobiliarioturístico condiciones favorables de expansión y rentabilidad.

El término "turismo residencial" fue empleado por primera vez en la literatura especializada por Jurdao (1979), con el fin de explicar las transformaciones sociales que tenían lugar en Mijas (Málaga) como consecuencia de la venta de suelo agrícola a empresarios urbanizadores. A partir de este concepto se han hecho importantes contribuciones al análisis de las urbanizaciones asociadas al turismo. Una de las definiciones más recientes es la de Aledo (2016), quien afirma que "el turismo residencial puede ser entendido como el conjunto de prácticas sociales que giran en torno a la producción social de segundas residencias, producción de infraestructuras, servicios y espacios próximos, y cuyo uso está mayoritariamente ligado a la esfera del ocio y no a la reproducción y producción" (p. 41).

A pesar de los desacuerdos en cuanto al concepto "turismo residencial" (Mateu i Lladó, 2003; Pontes \& Lima, 2011), ${ }^{2}$ el hecho es que existe una significativa producción inmobiliaria asociada a la expansión del turismo, y la discusión que estos autores desarrollan es pertinente y esclarecedora cuando afirman que el objetivo principal del turismo residencial es comprar suelo, construir residencias y venderlas. Es decir, los agentes involucrados no están ocupados en atraer turistas y ofrecer servicios; sí en generar suelo urbano a través de la producción y venta de bienes inmobiliarios.

Asociada a este factor explicativo de orden económico, es preciso mencionar la existencia de factores de orden sociocultural. Entre ellos, nuevos hábitos y comportamientos emergentes con las facilidades proporcionadas por el medio técnico, que ha impulsado los viajes a través de su bajada de precios y mayor rapidez. Se trata de

Para Mateu i Lladó (2003, p. 200) existe confusión entre lo que se considera "turista” y "residente". La complejidad de las nuevas formas de migración (lifestyle migration) verificadas en un mundo globalizado han contribuido a enredar y dificultar los límites entre lo que debe considerarse residente y/o turista. Pontes y Silva (2011) observan que un turista no crea lazos afectivos con el lugar, pues la relación con el entorno se establece de forma rápida y fugaz; mientras que el usuario de segunda residencia sí tiende a desarrollar relaciones afectivas y de sociabilidad con el entorno, pues retorna con frecuencia al lugar donde se localiza su domicilio de uso ocasional destinado al ocio y descanso. 
las nuevas modalidades de migración impulsadas no por factores de orden económico o político, sino por la búsqueda de localidades dotadas de parajes naturales con clima agradable y belleza paisajística: son las inmigraciones por comodidad o migraciones climáticas. Varios estudios han destacado estas nuevas formas de movilidad, posibilitadas por el avance técnico y los nuevos estilos de vida (lifestyle migration), tal como apuntan Benson y O’Reilly (2009) y Janoschka y Haas (2014), entre otros.

La globalización contribuye a la aproximación virtual de los lugares (Harvey, 1993) y a una mayor movilidad de las personas. Pese a ello, esta mayor integración del espacio global propiciada por los nuevos desplazamientos de naturaleza turística/migratoria hacia localidades dotadas de amenidades climáticas, fuertemente estimuladas por el sector inmobiliario, han originado nuevas formas de segregación, exclusión y separación socioespacial en el ámbito local.

\section{Resultados: la difusión del modelo de urbanización turística española hacia el Nordeste brasileńo}

Analizando la arquitectura y la urbanización emergentes en el período en que el turismo se volvió un fenómeno de masas y el litoral español pasó a ser frecuentado por visitantes procedentes de los países del norte de Europa, Martínez-Medina (2016) observó que, desde sus comienzos, el negocio inmobiliario se asocia al ocio. En su estudio, que comprende el periodo 1953-1979, constató que la producción de bienes inmobiliarios fue asumiendo distintas modalidades, con tipologías desarrolladas simultáneamente; en especial, habitaciones unifamiliares aisladas y edificios plurifamiliares (bloques y torres). Los edificios altos fueron implantados en la década de 1960. El autor seńala que, en general, las unidades unifamiliares se adaptaban a los terrenos más accidentados, mientras los bloques eran construidos en los terrenos más planos frente al mar. $\mathrm{Al}$ respecto, apunta a modo de síntesis:

Estas tipologías generan diferentes modelos urbanos que se resumen en dos conceptos que se suponen extremos: ciudad horizontal (extensión y superficie) frente a la ciudad vertical (intensidad y altura) con todas las variantes híbridas intermedias; ambos modelos pueden funcionar como "ciudades de veraneo", con propiedad de inmuebles para la permanencia de largas temporadas; o como ciudades turísticas, con hoteles y apartamentos de alquiler para visitas más cortas. (p. 172)

Mazón (2016), analizando el desarrollo turístico de Alicante, observa que a lo largo del siglo xx su expansión está estrictamente ligada a un creciente proceso especulativo del suelo, con total anuencia del poder público. Esta asociación se fue intensificando, especialmente con la proliferación del turismo de masas, después de finales de la década de 1950, y la producción inmobiliaria se difundió por toda la costa mediterránea. A partir de 1970 se verifica el crecimiento de la producción de segundas residencias a lo largo del litoral espańol, lo que, según Aledo (2016), constituye la primera fase del denominado "turismo residencial". El autor identificó cinco fases de turismo residencial (véase tabla 2). Señala que, a lo largo del tiempo, a medida que las urbanizaciones asumen mayor dimensión, magnitud y complejidad, van 
adentrándose en los municipios interiores (prelitorales) e incorporando áreas anteriormente destinadas a actividades agrícolas, como es el caso de la Región de Murcia.

A mediados de la década de 1990 (tercera fase), se produce una nueva modalidad de desplazamiento poblacional, caracterizado por un tipo de inmigración basado en la búsqueda de lugares dotados de bonanza climática, denominado por Benson y O’Reilly (2009) como de inmigración por estilo de vida (lifestyle inmigrants). Ingleses, alemanes, franceses y de otros países europeos adquieren residencias en el litoral mediterráneo para pasar en ellas largas temporadas, ayudando este movimiento social a la dinamización del mercado inmobiliario español. Los proyectos de urbanizaciones turísticas pasaron a incluir una serie de servicios y equipamientos de ocio, con millares de unidades de viviendas en los resorts privados.

\begin{tabular}{|c|c|c|c|}
\hline FASE & LOCALIZACIÓN & TIPOLOGÍA & CARACTERÍSTICA URBANÍSTICA \\
\hline $\begin{array}{l}1^{\text {a }} \text { fase: } \\
\text { mediados de } \\
1970 / \text { inicio } \\
\text { de } 1980\end{array}$ & $\begin{array}{l}\text { Primera línea de } \\
\text { playa. }\end{array}$ & $\begin{array}{l}\text { Pequeña urbani- } \\
\text { zación dispersa } \\
\text { y bloques de } \\
\text { apartamentos. } \\
\end{array}$ & $\begin{array}{l}\text { - Desarrollo en altura: construcción de edifi- } \\
\text { cios de apartamentos. } \\
\text { - Murallas de cemento a lo largo da costa. }\end{array}$ \\
\hline $\begin{array}{l}2^{\text {a fase: }} \\
\text { inicio de } \\
1980 / 1991- \\
1994\end{array}$ & $\begin{array}{l}\text { Se comienza a } \\
\text { ocupar el hinterland } \\
\text { de las ciudades } \\
\text { turísticas costeras. }\end{array}$ & $\begin{array}{l}\text { Urbanización } \\
\text { compuesta por } \\
\text { decenas de bunga- } \\
\text { lows y adosados. }\end{array}$ & $\begin{array}{l}\text { - Apareció un nuevo modelo: urbanización } \\
\text { formada por agrupaciones de chalets, adosados } \\
\text { y bungalows. } \\
\text { - Unidad urbanística separada de los cascos } \\
\text { urbanos tradicionales. }\end{array}$ \\
\hline $\begin{array}{l}3^{a} \text { fase: } \\
1994 \text { hasta } \\
2001\end{array}$ & $\begin{array}{l}\text { Municipios de } \\
\text { segunda y tercera } \\
\text { línea da playa, dis- } \\
\text { putando los terrenos } \\
\text { a las actividades } \\
\text { agrícolas. }\end{array}$ & $\begin{array}{l}\text { Urbanización con } \\
\text { campo de golf. }\end{array}$ & $\begin{array}{l}\text { - Lifestyle inmigrants. } \\
\text { - Abarca gran cantidad de suelo, dada la } \\
\text { magnitud de los proyectos y servicios que } \\
\text { incorpora. } \\
\text { - Hoteles de } 4 \text { o } 5 \text { estrellas. }\end{array}$ \\
\hline $\begin{array}{l}4^{a} \text { fase: } \\
2002-2008\end{array}$ & & $\begin{array}{l}\text { Resort turístico } \\
\text { residencial. }\end{array}$ & $\begin{array}{l}\text { - Nuevo Turismo Residencial (NTR). } \\
\text { - Modelo de la macrourbanización: miles de } \\
\text { viviendas, con producto residencial dotado de } \\
\text { servicios e infraestructuras más completos. } \\
\text { - Nuevo entorno turístico: exclusivo, privatiza- } \\
\text { do y centrípeto. } \\
\text { - Estructura cerrada, con fuertes medidas de } \\
\text { seguridad. } \\
\text { - Dotados de importantes infraestructuras. } \\
\text { - Unidad de ocio residencial privatizada, } \\
\text { autónoma e independiente del territorio en } \\
\text { que se localizaba. } \\
\text { - Nueva tourist bubble, que adaptaba el } \\
\text { concepto del "hotel todo incluido" al turismo } \\
\text { residencial. }\end{array}$ \\
\hline $\begin{array}{l}5 \text { a fase: } \\
2008- \\
\text { actualidad }\end{array}$ & $\begin{array}{l}\text { Paralización de los } \\
\text { proyectos. }\end{array}$ & & \\
\hline
\end{tabular}

TABLA 2 | Fases en la evolución del turismo residencial español FUENTE: ADAPTADO DE ALEDO (2OI6)

Según Fernández y Cruz (2011), varios factores han ayudado al aumento del proceso urbanizador en España a partir de 1990. Destacan: i) crecimiento económico y demográfico; ii) escenario financiero favorable; iii) vivienda como bien de inversión; 
iv) orientación del mercado de la vivienda en dirección a la propiedad y a la segunda residencia; v) adquisición de moradas por geronto-inmigrantes o inmigrantes climáticos; vi) impactos de reformas en la legislación del suelo; y vii) debilidad de contestación social del modelo adoptado. Todos estos factores han posibilitado el fuerte crecimiento de la producción de bienes inmobiliarios en el territorio espańol. Por ello, es importante destacar que la disponibilidad de capital para financiar inmuebles a bajo coste y sin muchas exigencias para dar créditos (lo que desencadenó la crisis iniciada en 2008), favoreció fuertemente la expansión del mercado inmobiliario. Según el estudio mencionado, mientras que en los países miembros de la Unión Europea se construyeron 5.000 viviendas residenciales por cada millón de habitantes, en España se edificaron 18.000. Sin duda, las segundas residencias destinadas al ocio favorecieron significativamente el crecimiento de la producción inmobiliaria. Basándose en los datos del Observatorio de la Sostenibilidad en España, Aledo (2016) afirma que en las provincias de Alicante, Valencia y Málaga las residencias con potencial uso turístico representaban en la época la mitad del parque inmobiliario. Además, certifica que entre 1991 y 2003 ocurrió un crecimiento del 40,6\% del total de las residencias de los municipios litorales mediterráneos.

Tal y como indica García (2008), la Región de Murcia contaba en 2006 con proyectos que sumaban 308.959 unidades residenciales en urbanizaciones autónomas, la mayoría con campos de golf asociado (totalizando 61), y se pronosticaba que serían utilizados por una población estimada de 938.877 usuarios de segundas residencias. Como consecuencia de la crisis económica y financiera, en su mayor parte estos proyectos no se han llevado a cabo. Actualmente, en la Región de Murcia existen 54 viviendas totales por cada 100 habitantes, de las que 18 no son residencia principal (segundas residencias, desocupadas o vacías). Por otra parte, resulta de interés indicar que un 16\% de las viviendas vendidas en la Región de Murcia son adquiridas por ciudadanos extranjeros (principalmente procedentes de la Unión Europea). Este último dato se ve sobrepasado solamente por las cifras relativas a las comunidades autónomas de Valencia (26\%), Canarias (28\%) y Baleares (35\%). ${ }^{3}$

En el año 2000 comienza la etapa del nuevo turismo residencial (Aledo, 2016), con grandes urbanizaciones cerradas y exclusivas, con servicios de ocio incluidos. Se produce, entonces, la difusión del modelo hacia el Nordeste de Brasil (Demajorovic, Aledo, Landi \& Mantovani, 2011), constituyéndose los españoles como los principales inversores, al edificar urbanizaciones similares a las de la costa mediterránea española. Además, personas procedentes de España comienzan a adquirir bienes inmobiliarios destinados a uso particular o especulación.

En Brasil, el turismo y el fenómeno de la segunda residencia se expande y se constituye como vector de transformación espacial sobre todo a partir de 1970 en la Región Sudeste, dirigiéndose hacia el sur en la década siguiente, y finalmente en 1990 al Nordeste (Silveira \& Rodrigues, 2015). Según datos del Instituto Brasileńo de Geografía y Estadística (IBGE), entre los años 2000 y 2010 la Región Nordeste tuvo un mayor crecimiento porcentual de segundas residencias en comparación

Las cifras porcentuales han sido calculadas a partir de los datos ofrecidos por el Instituto Nacional de Estadística (INE) de España, 2016. 
con las demás: Nordeste (74\%), Norte (72\%), Centro Oeste (62\%), Sur (35\%) y Sudeste $(35 \%)$.

Es en el contexto de implantación del Estado neoliberal, a lo largo de la década de 1990, cuando el turismo pasa a ser estimulado con la creación de polos turísticos. El Nordeste brasileño fue objeto de inversiones en carreteras, aeropuertos, saneamiento y otras infraestructuras urbanas a través del Programa de Desarrollo del Turismo en el Nordeste Brasileño (Prodetur/Ne) y, posteriormente, del Programa de Aceleración del Crecimiento (PAC), generándose con ello las condiciones para la expansión del turismo nacional e internacional (Pontes, Santos \& Nunes, 2016).

En el contexto de internacionalización del turismo nordestino, y una vez que la costa mediterránea se encontró saturada y con precios muy elevados, a partir del año 2000 se inicia la llegada de inversores europeos del sector inmobiliario al Nordeste brasileño, en busca de nuevas oportunidades de negocios sustentadas en cadenas hoteleras pertenecientes a redes globales y de flujos turísticos internacionales (Pontes \& Silva, 2012). Es decir, la facilidad de obtención de créditos a bajo coste en el sector financiero, sumada a los bajos precios de los inmuebles en el mercado nordestino, atrajo inversores europeos.

El turismo proporcionó un acelerado crecimiento al mercado inmobiliario en el litoral de Potiguar. Inicialmente, las inversiones se concentraron en la principal área turística: el Barrio de Ponta Negra (Natal), y la producción de bienes inmobiliarios quedó a cargo de las constructoras nacionales, pero a partir de empresas extranjeras asociadas a ellas. El primer edificio del Barrio data de 1995 (Edificio Olimpo), y posteriormente se produjo un acelerado proceso de verticalización (Pinheiro, 2011). En la década de 1990 se construyeron 13 edificios en este lugar, mientras que entre 2000 y 2013 se levantaron 82 (Costa \& Oliveira, 2016).

A lo largo del último decenio, las inversiones inmobiliarias se han diseminado por toda la costa Potiguar. A continuación se presentarán algunos datos estadísticos obtenidos en la investigación realizada en seis municipios localizados en el litoral norte de Natal (Extremoz, Ceará-Mirim, Maxaranguape, Rio do Fogo, Touros e São Miguel do Gostoso) entre 2000 y 2013.

Los primeros inversores con capital foráneo procedían de Europa, especialmente de Portugal, España e Italia. Posteriormente llegaron inversores escandinavos (Noruega y Suecia) y de otros países, como se observa en la tabla 3. Se constata la actuación de 99 empresas de 18 nacionalidades diferentes en negocios inmobiliarios en los municipios investigados. Destacan las empresas portuguesas (26), que efectuaron 164 transacciones; espańolas (20), con 81; italianas (19), con 43; y noruegas (10) con 64 transacciones ejecutadas a lo largo del periodo analizado. Junto a ellas existen otras compañías, originarias del continente americano y de Asia-Oceanía (tabla 3).

\begin{tabular}{|l|c|c|}
\hline \multicolumn{1}{|c|}{ NACIONALIDAD } & NÚMERO DE EMPRESAS & NÚMERO DE TRANSACCIONES \\
\hline Portuguesa & 26 & 164 \\
\hline Espańola & 20 & 81 \\
\hline Italiana & 19 & 43 \\
\hline Noruega & 10 & 64 \\
\hline
\end{tabular}

(continúa) 
(continuación)

\begin{tabular}{|l|c|c|}
\hline \multicolumn{1}{|c|}{ NACIONALIDAD } & NÚMERO DE EMPRESAS & NÚMERO DE TRANSACCIONES \\
\hline Británica & 6 & 8 \\
\hline Sueca & 4 & 3 \\
\hline Alemana & 1 & 1 \\
\hline Belga & 1 & 1 \\
\hline Suiza & 1 & 1 \\
\hline Danesa & 91 & 433 \\
\hline Subtotal Europa & 1 & 1 \\
\hline Ecuatoriana & 1 & 2 \\
\hline Argentina & 1 & 1 \\
\hline Barbadense & 1 & 1 \\
\hline Estadounidense & 4 & 5 \\
\hline Subtotal América & 1 & 1 \\
\hline Rusa & 1 & 1 \\
\hline Afgana & 1 & 1 \\
\hline Libanesa & 1 & 1 \\
\hline Marshalesa & 4 & 4 \\
\hline Subtotal Asia-Oceanía & 99 & 442 \\
\hline Total & & \\
\hline
\end{tabular}

TABLA 3 | Número de transacciones inmobiliarias realizadas por empresas extranjeras (2000-2013)

FUENTE: ELABORACIÓN PROPIA A PARTIR DEL TRABAJO DE CAMPO

La tabla 4, a continuación, sintetiza para cada municipio del área estudiada el número de transacciones realizadas según la procedencia de las empresas inversoras. Así, las espańolas se localizan principalmente en Rio do Fogo, Ceara-Mirim y Maxaranguape. No obstante, solo lideran la estadística en Ceara-Mirim. Por su parte, en Rio do Fogo y Maxaranguape predominan las portuguesas y noruegas, respectivamente.

A pesar de que Portugal concentra el mayor número de empresas con presencia en la compraventa de inmuebles, Espańa se encuentra en primer lugar en relación con el número de transacciones efectuadas (467), seguido de Portugal (428), Noruega (344) e Italia (306). Pese a que aparecen compradores de varios países, predominan las naciones mediterráneas y nórdicas.

Con relación a los valores comercializados, que totalizaron $\mathrm{R} \$ 379.113 .589,00$ en valores nominales, los espańoles aparecen en primer lugar con un montante de R\$ 98.806.973,00; tras ellos, los italianos, con R\$ 43.629.454,00; los portugueses, con R\$ 37.658.164,00; y los noruegos con R\$ 32.320.400,00 (tabla 5). ${ }^{4}$ Sin duda, existe un protagonismo de los españoles en la dinámica inmobiliaria de Polo Costa das Dunas en la última década.

4 Como la investigación hace referencia a valores nominales, es decir, sin corrección inflacionaria, posiblemente los menores valores del conjunto de las transacciones portuguesas obedecen al hecho de haber sido los primeros en efectuar las transacciones inmobiliarias. En la medida en que las tierras van ganando valor, se observa una disminución de su participación y el aumento de otras nacionalidades, como, por ejemplo, de los noruegos. 


\begin{tabular}{|l|l|c|}
\hline \multirow{4}{*}{ MUNICIPIO } & \multicolumn{1}{|c|}{$\begin{array}{c}\text { NACIONALIDAD DE LA } \\
\text { EMPRESA INVERSORA }\end{array}$} & TRANSACCIONES \\
\hline \multirow{4}{*}{ Ceara-Mirim } & Espańola & 22 \\
\cline { 2 - 3 } & Portuguesa & 8 \\
\cline { 2 - 3 } & Italiana & 9 \\
\cline { 2 - 3 } & Sueca & 9 \\
\hline \multirow{4}{*}{ Extremoz } & Espańola & 10 \\
\cline { 2 - 3 } & Portuguesa & 31 \\
\cline { 2 - 3 } & Italiana & 18 \\
\hline \multirow{4}{*}{ Rio do Fogo } & Espańola & 42 \\
\cline { 2 - 3 } & Portuguesa & 8 \\
\cline { 2 - 3 } & Italiana & 58 \\
\cline { 2 - 3 } & Sueca & 59 \\
\cline { 2 - 3 } & Noruega & 23 \\
\hline \multirow{2}{*}{ Touros } & Española & 91 \\
\cline { 2 - 3 } & Portuguesa & 1 \\
\cline { 2 - 3 } & Noruega & 8 \\
\hline \multirow{2}{*}{ Såo Miguel do Gostoso } & Espańola & 5 \\
\cline { 2 - 3 } & Portuguesa & 1 \\
\cline { 2 - 3 } & Española & 8 \\
\hline
\end{tabular}

TABla 4 | Transacciones realizadas en los municipios de Costa das Dunas según la nacionalidad de la empresa inversora

FUENTE: ELABORACIÓN PROPIA A PARTIR DEL TRABAJO DE CAMPO

\begin{tabular}{|l|c|c|c|c|c|c|c|}
\hline $\begin{array}{c}\text { NACIONA- } \\
\text { LIDAD }\end{array}$ & $\begin{array}{c}\text { EXTRE- } \\
\text { MOZ }\end{array}$ & $\begin{array}{c}\text { CEARÁ } \\
\text { MIRIM }\end{array}$ & $\begin{array}{c}\text { MAXARAN- } \\
\text { GUAPE }\end{array}$ & $\begin{array}{c}\text { RIO DO } \\
\text { FOGO }\end{array}$ & TOUROS & $\begin{array}{c}\text { S. M. DO } \\
\text { GOSTOSO }\end{array}$ & TOTAL \\
\hline Española & 5.568 .500 & 5.082 .940 & 73.518 .633 & 4.816 .000 & 1.248 .950 & 8.571 .950 & 98.806 .973 \\
\hline Italiana & 13.448 .212 & 1.513 .794 & 24.278 .000 & 2.042 .000 & 331.000 & 2.016 .448 & 43.629 .454 \\
\hline Portuguesa & 3.781 .000 & 2.881 .800 & 9.129 .774 & 9.660 .815 & 10.689 .250 & 1.515 .525 & 37.658 .164 \\
\hline Noruega & 1.350 .000 & - & 22.878 .640 & 8.091 .760 & - & - & 32.320 .400 \\
\hline Inglesa & 467.500 & - & 22.029 .545 & - & 685.856 & 928.335 & 24.111 .236 \\
\hline Singapur & - & 6.375 .914 & - & - & - & - & 6.375 .914 \\
\hline Sueca & - & 872.500 & 4.507 .441 & - & - & - & 5.379 .941 \\
\hline Otras & 4.727 .698 & 5.088 .332 & 4.632 .672 & 1.204 .000 & 1.783 .630 & 4.078 .000 & 21.514 .332 \\
\hline Brasileña & 9.815 .165 & 3.477 .468 & 62.202 .510 & 7.151 .000 & 6.647 .000 & 20.024 .032 & 109.317 .175 \\
\hline TOTAL & 39.158 .075 & 25.292 .748 & 223.117 .215 & 32.965 .575 & 21.385 .686 & 37.134 .290 & 379.113 .589 \\
\hline
\end{tabular}

TABLA 5 | Cantidades invertidas en los municipios de estudio, según nacionalidad y en moneda brasileña $(\mathbf{R} \$)^{*}$

FUENTE: ELABORACIÓN PROPIA CON BASE EN EL TRABAJO DE CAMPO. COMO LA INVESTIGACIÓN FUE SOBRE LAS TRANSACCIONES DE INMUEBLES INCLUYENDO EXTRANJERAS (COMPRA Y/O VENTA), ALGUNAS VECES LOS INMUEBLES ERAN VENDIDOS POR EXTRANJEROS A BRASILEÑOS, ESPECIALMENTE DESPUÉS DE LA CRISIS DE 2008

LOS VALORES OSCILARON EN EL PERÍODO DE LA INVESTIGACIÓN. EL OI/OI/2000, CUANDO SE INICIÓ LA PESQUISA, I,OO USD = I,78 BRL; Y EL 30/I2/20I3, FECHA DE CONCLUSIÓN, I,OO $\mathrm{USD}=2,34 \mathrm{BRL}$ 
En el periodo analizado se realizaron 2.261 transacciones, que involucraron a empresas y clientes particulares extranjeros. Maxaranguape englobó aproximadamente el 30\% de ellas y el $60 \%$ de las inversiones, con una mayor actuación de empresas de varias nacionalidades. El litoral de los municipios más próximos a Natal fue el territorio más demandado para la adquisición de inmuebles por extranjeros. Por su parte, Touros y São Miguel do Gostoso, más alejados, tuvieron una importancia menor.

En relación con la tipología de las transacciones, el 79,21\% de los inmuebles comercializados pertenecía a la categoría de lote/terreno (1.791), seguidos de casas (195), chalets (166), apartamentos (84) y edificios (25). Probablemente, la mayor búsqueda en la adquisición de lotes/terrenos indica el interés de los propietarios en especular.

Las empresas extranjeras que comienzan a operar en el mercado de inmuebles de la zona introducen una novedad en lo referido a las unidades habitacionales destinadas al ocio y dirigidas a satisfacer una demanda internacional: los condominios cerrados, correspondientes a las urbanizaciones/resorts, que proliferaron en el litoral. Este patrón de segundas residencias fue llevado a Polo Costa das Dunas por empresas que comenzaron a actuar en el mercado inmobiliario regional.

El patrón de segundas residencias existente hasta entonces se caracterizaba por ser unidades aisladas con una misma tipología en la edificación (figura 3). Otros condominios fueron construidos con una arquitectura totalmente exógena al entorno (figura 4); entre ellos, los ubicados en el litoral mediterráneo español (figura 5).

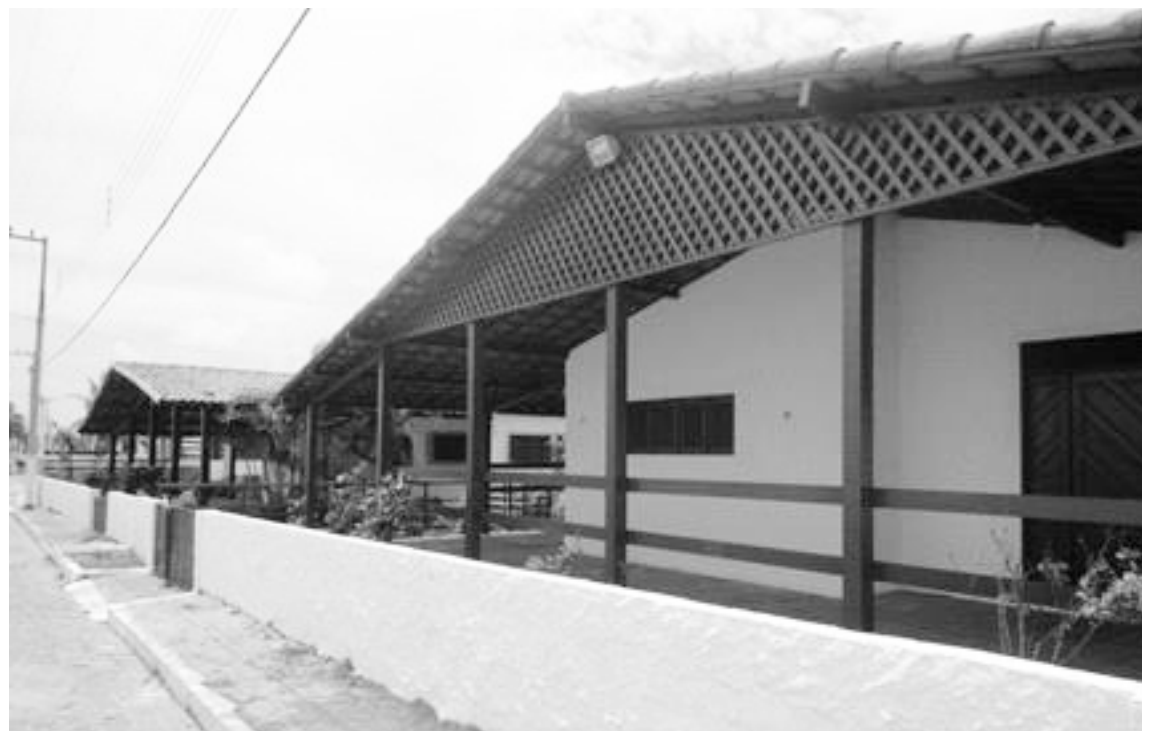

FIGURA 3 | Patrón de modelo convencional de segundas residencias (unidades aisladas) en Pitangui

FUENTE: FOTOGRAFÍA DE LOS AUTORES 


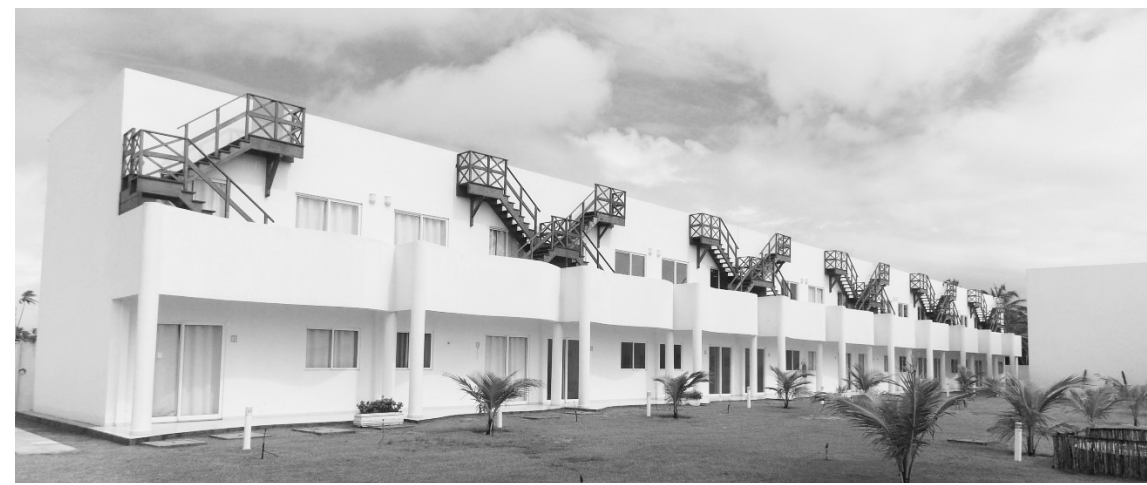

FIgURA 4 | Segundas residencias de arquitectura exógena en Pitangui, siguiendo el patrón edificador español

FUENTE: FOTOGRAFÍA DE LOS AUTORES

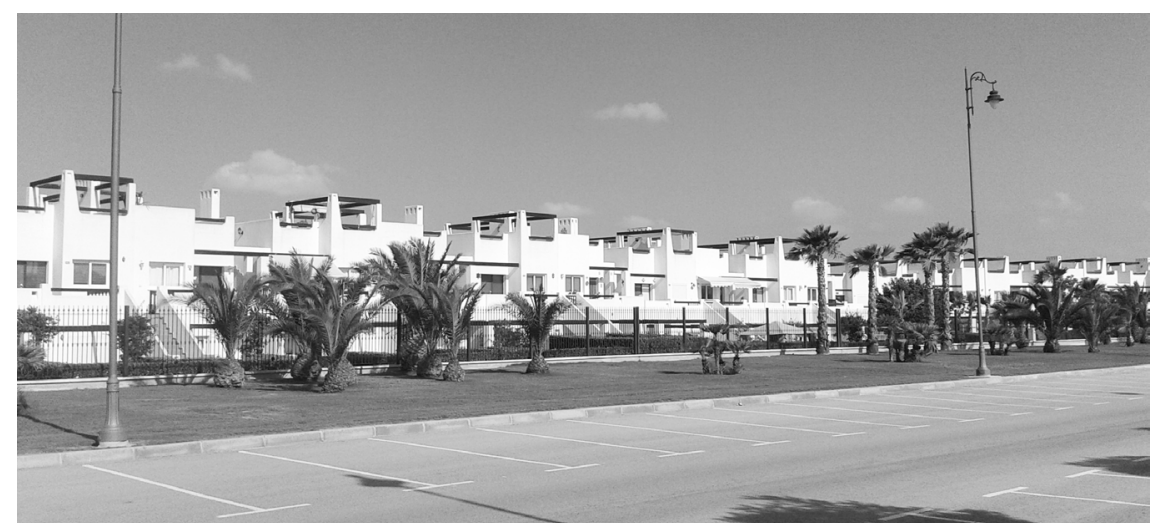

FIgURA 5 | Segundas residencias en la Urbanización Condado de Alhama (Costa Cálida, España)

FUENTE: FOTOGRAFÍA DE LOS AUTORES

En Rio do Fogo, inversores portugueses (Recanto do Zumbi, Zumbi Beach Resort y Praia de Zumbi) construyeron tres condominios cerrados, donde destaca la adquisición de unidades habitacionales por noruegos para fines de ocio e inversiones. Así, los extranjeros adquirían lotes/terrenos en parcelas eriales. No obstante, cuando se trataba de unidades construidas (segundas residencias), preferían los condominios cerrados. A pesar de la magnitud de las inversiones verificadas en Polo Costa das Dunas, sus montos han sido muy inferiores a los registrados en el litoral español. Pese a ello, fueron suficientes para introducir elementos similares a los encontrados en el modelo hispano, como urbanizaciones con acceso restringido.

En relación con la actuación del Estado, se constatan acciones destinadas a crear infraestructuras de accesibilidad (carreteras y aeropuertos) con el fin de viabilizar la atracción de inversiones, cuestiones estas ya discutidas por Pontes (2007), Pontes y Silva (2012), Pontes, Santos y Nunes (2016) para Polo Costa das Dunas, y por Serrano Martínez, Espejo Marín y García Marín (2016) para la Región de Murcia. 


\section{Conclusiones}

Tras analizar el turismo residencial en la Costa Cálida y en Polo Costa das Dunas, se extrae que en ambos territorios se ha producido una serie de consecuencias territoriales y socioeconómicas similares. La primera de ellas es la revalorización del suelo. De acuerdo con Huete (2008), este fenómeno se genera ante cualquier proceso de urbanización, y podría pensarse que los principales beneficiarios de la mencionada revalorización del suelo son los propietarios de terrenos. Sin embargo, tanto en la Costa Cálida como en Polo Costa das Dunas, los sitios son adquiridos a un precio muy bajo por las empresas constructoras, que han sido las principales beneficiarias por la venta de las numerosas viviendas edificadas.

La presencia de estas urbanizaciones ha supuesto la necesidad de nuevos servicios públicos (mejoras en carreteras, alumbrado público o mejora en la red de saneamiento) en los lugares donde han sido edificadas, por lo que se han incrementado los gastos de los ayuntamientos donde se localizan. No obstante, conviene mencionar que los nuevos residentes generan una estimulación de la economía y el comercio local.

Otra consecuencia similar entre ambos destinos es la paralización de la construcción de complejos residenciales. En el caso español, debido al estallido de la burbuja inmobiliaria en 2008, muchas viviendas se quedaron a medio edificar o sin iniciar sus obras por la quiebra de las empresas constructoras. En lo que respecta al nordeste brasileño, se conjugaron dos factores: la dificultad para conseguir una licencia medioambiental para construir y la falta de liquidez de las promotoras europeas, condiciones que impidieron el desarrollo de numerosos proyectos residenciales. En este sentido, procede mencionar que en la Costa Cálida y Polo Costa das Dunas muchos ciudadanos han perdido parte de su dinero al comprar viviendas que nunca se edificaron o no se llegaron a finalizar. Llama la atención el caso de los jubilados británicos en la España mediterránea. En su mayoría compraron sus casas entre 1999 y 2008, cuando 1 libra esterlina equivalía a 1,5 euros. Entonces, una casa de 200.000 euros les costaba 133.000 libras esterlinas, y una pensión de 1.000 libras esterlinas suponía 1.500 euros. Este colectivo podía permitirse comprar casas caras en España y vivir con pensiones relativamente bajas. Pero desde el año 2008, la depreciación de la libra frente al euro ha supuesto aproximadamente un 30\% de descuento en los ingresos de los pensionistas del Reino Unido. Es decir, muchos no ganan suficiente dinero para vivir en España y pagar una hipoteca, y tienen necesidad de retornar a su país. Sin embargo, algunos se encuentran "atrapados" en el lugar de destino, porque vendieron su casa original y ahora no logran revender la adquirida en España, ni siquiera a un precio más bajo (Huete, Mantecón \& Estévez 2013).

También es necesario hacer hincapié en los impactos medioambientales del turismo residencial. La degradación del paisaje -principal recurso de los territorios estudiados, junto con el clima- es uno de los más evidentes, puesto que se ha constatado la pérdida de atractivos en playas debido a la masificación turística. Además, en la Costa Cálida, en épocas de sequía se produce un conflicto por el agua, recurso estratégico para las actividades agrícolas y, desde hace varios ańos, para los campos de golf de los resorts construidos. 
Por último, conviene destacar que se ha identificado una serie de procesos socioespaciales urbanos en las zonas estudiadas. Destacan los siguientes:

- Diferenciación: tanto en la Costa Cálida como en Polo Costa das Dunas, los propietarios de los resorts suelen tener un mayor poder adquisitivo que la población local. Es decir, la distinción social y la diferenciación de clase continúan manifestándose en la práctica turística. De acuerdo con Mazón (2016), los destinos turísticos surgen en función de peculiaridades o singularidades naturales o creadas, las cuales ejercen una fuerza de atracción de las personas que pasan a frecuentar la localidad, originando flujos turísticos. La competitividad lleva consigo la búsqueda de innovación; por ello, los municipios están siempre dispuestos a diferenciarse, creando nuevos elementos de atracción para ofrecer productos novedosos con cualidades especiales (Pontes, 2005). En este sentido, la Costa Cálida y Polo Costa das Dunas buscaron distinguirse de otros destinos turísticos mediante la construcción de resorts.

- Homogeneización: actualmente existe una tendencia a la homogeneización de las localidades turísticas, en la medida en que otros destinos tienden a copiar aquellos productos con gran aceptación en el mercado. La homogeneización referida es siempre parcial y nunca alcanzada plenamente, ya que el espacio es diferenciado en sus distintas dimensiones: económica, social, política, cultural y natural. Así, la actividad turística se fundamenta en la diferenciación de la experiencia que puede proporcionar al turista. Sin embargo, el funcionamiento del mercado promueve cierta homogeneización de los lugares, especialmente cuando se trata de un turismo masivo, ofreciendo productos bastante similares en lo que se refiere a los servicios (cadenas hoteleras, restaurantes y tiendas de souvenires), dando lugar a espacios con características parecidas. En la investigación se comprobó que, pese a tener dimensiones menores, el modelo de las urbanizaciones cerradas (resorts/condominios) introducido en Brasil reproduce patrones de arquitectura exógenos propios de la costa mediterránea. Por tanto, se extrae que la búsqueda de la diferenciación y la tendencia a la homogeneización constituyen constantes que retroalimentan los destinos turísticos.

- Segregación: en las realidades estudiadas ocurren procesos de confinamiento y autosegregación espacial (resorts, urbanizaciones privadas, condominios y privatización de los espacios), derivados del turismo. Estas urbanizaciones congregan en su interior una población que tiende a una homogeneización ética y cultural (guetos), como es el caso de los ingleses en la Costa Cálida y de los noruegos en Polo Costa das Dunas. El contraste es bastante visible cuando los nuevos inmigrantes hablan otra lengua, tienen otros hábitos y costumbres y se autosegregan en las urbanizaciones, acentuando la diferencia entre ellos y la comunidad local. En los centros turísticos, la diferenciación sociocultural comúnmente ha implicado la segregación espacial.

- Fragmentación: la fragmentación está relacionada con la idea de un todo que se rompe en partes. Las urbanizaciones analizadas se encuentran aisladas del núcleo urbano compacto, incidiendo en una mayor fragmentación del espacio urbano, 
y ello tanto en la Costa Cálida como en Polo Costa das Dunas. Los resorts de estos territorios tienen un número elevado de unidades habitacionales, pero como son de uso temporal no hay una demanda que justifique la implementación de comercios (panaderías, fruterías) o servicios colectivos y personales (colegios e institutos de educación secundaria o centros de salud, por ejemplo), constituyéndose en un espacio urbano bastante especializado en relación con su función. Es decir, los resorts no asumen una función comercial, de modo que ciertos productos y servicios deben ser adquiridos en otras áreas que alcanzan una centralidad comercial. Las restricciones para la circulación de personas no residentes en las urbanizaciones de segundas residencias observadas en las dos realidades favorecen la creación de una ciudad cada vez más fragmentada.

- Dispersión: de acuerdo con Spósito (2009), actualmente el fenómeno de la dispersión urbana no se restringe a las grandes metrópolis. Los espacios urbanos de diferentes dimensiones demográficas y funciones pasan por estos cambios. Se trata, efectivamente, de nuevas formas de producir y apropiarse del espacio, con impactos importantes en la vida económica y social, sobre todo en la constitución de nuevos hábitats residenciales. La dispersión del tejido urbano fue fuertemente influenciada por la dinámica del turismo, que potenció e indujo el proceso de urbanización a lo largo de la línea costera tanto en la Costa Cálida como en el nordeste brasileño.

- Gentrificación: el fenómeno de la gentrificación se ha desarrollado en las grandes metrópolis, pero también en otros espacios urbanos y en el campo. En el caso que nos ocupa, se corrobora un proceso de valorización de determinadas áreas que asumen la función turística, comúnmente patrocinada por el poder público. Acontece la sustitución de determinados grupos sociales por otros, y también las actividades comerciales son reemplazadas por tiendas gourmet, fast foods y cadenas que comercializan productos similares en diversas ciudades del mundo. En muchas zonas litorales, este proceso puede ser identificado en la medida en que el turismo desencadena la deslocalización poblacional y de actividades comerciales tradicionales, substituyéndolas por otras más selectas, tal como ocurrió en Pipa (Tibau do Sul) y en Vila de Ponta Negra (Natal), destinos turísticos en Polo Costa das Dunas; o con la construcción de los resorts en el Campo de Cartagena, zona eminentemente agrícola de la Costa Cálida.

- Valorización: el turismo promueve la valorización de las áreas que participan en el sistema turístico y potencia las actividades inmobiliarias, dinamizando el mercado (Fernández-Tabales \& Cruz, 2013). En el caso de Polo Costa das Dunas, la actividad turística contribuyó a su inserción en el mercado global, atrayendo inversores de diversos lugares. El boom inmobiliario fue mencionado por varios autores (Nunes, 2014; Santos, 2015; Silva, 2010), promoviendo una acelerada inflación en los precios de los terrenos en varias localidades del litoral. En la costa mediterránea este proceso especulativo fue tan intenso, que algunos autores lo denominaron "tsunami urbanizador” (Gaja I Díaz, 2008; Tabales \& Mazo, 2011). En la Región de Murcia, García (2008) relata que áreas sin actividad productiva debido a la constitución edáfica del suelo, pasan por un 
proceso de valorización a través de la construcción de enormes resorts con una gran cantidad de viviendas secundarias.

\section{Referencias bibliográficas}

Aledo, A. (2016). Turismo residencial y vulnerabilidad en el interior del Levante español. En J. Gascón \& E. Cañada (coords.), Turismo residencialy gentrificación rural (pp. 37-60). El Sauzal (Tenerife): PASOS, Revista de Turismo y Turismo Cultural / Foro de Turismo Responsable. http://www.pasosonline.org/Publicados/pasosoedita/PSEdita_16_Definitivo _e-book.pdf

Aledo, A., Mazón, T. \& Mantecón, A. (2007). La insostenibilidad del turismo residencial. En D. Lagunas (ed.), Antropología y turismo: claves culturales y disciplinares (pp. 185-208), México, D.F.: Plaza y Valdés. https://rua.ua.es/dspace/bitstream/10045/13869/1/ turismo\%20residencial.pdf

Assis, L. F. (2009). Segundas residencias y multiterritorialidad en el nordeste brasileño: el aumento del turismo residencial. En T. Mazón, R. Huete \& A. Mantecón (eds.), Turismo, urbanización y estilos de vida. Las nuevas formas de movilidad residencial (pp. 175-192). Barcelona: Icaria. https://bit.ly/2U0bGqu

Benson, M. \& O’Reilly, K. (2009). Lifestyle migration. Expectations, aspirations and experiences. Farnham, Reino Unido: Ashgate.

Brito Henriques, E. (2003). A cidade, destino de turismo. Revista da Faculdade de Letras, Geografia, 19, 163-172. https://ler.letras.up.pt/uploads/ficheiros/312.pdf

Cabrerizo, C. C. (2016). La ciudad negocio: Turismo y movilización social en pugna. Madrid: Cisma Editorial.

Costa, A. A. \& Oliveira, V. M. (2016). A verticalização e o mercado imobiliário: um estudo sobre o bairro de Ponta Negra em Natal/RN, Brasil. En E. M. Furtado \& N.P. Santos (eds.), O pensamento de Milton Santos e a geografia brasileira (pp. 137-152). Natal, Brasil: edufrn (Editora da Universidade Federal do Rio Grande do Norte).

Cruz, R. (2009). Los nuevos escenarios del turismo residencial en Brasil: un análisis crítico. En T. Mazón, R. Huete \& A. Mantecón (eds.), Turismo, urbanización y estilos de vida. Las nuevas formas de movilidad residencial (pp. 161-174). Barcelona: Icaria. https://bit. ly/2Fily5x

Demajorovic, J., Aledo, A., Landi, B. \& Mantovani, A. L. (2011). Complejos turísticos residenciales. Análisis del crecimiento del turismo residencial en el Mediterráneo español y en el Litoral Nordestino (Brasil) y su impacto socio-ambiental. Estudios y Perspectivas en Turismo, 20(4), 772-796. http://www.estudiosenturismo.com.ar/PDF/ V20/N04/v20n4a02.pdf

Espejo, C. \& Cànoves, G. (2011). Política de usos del agua en los campos de golf en España. Documents d'Anàlisi Geogràfica, 57(2), 255-277. https://doi.org/10.5565/rev/dag.278

Fernández, A. \& Cruz, E. (2011). Territorio y actividad constructora: del 'Tsunami’ a la crisis. Factores explicativos y propuesta de indicadores a escala municipal en Andalucía. Boletín de la Asociación de Geógrafos Españoles, (56), 79-110. https://www.age-geografia. es/ojs/index.php/bage/article/view/1345/1268 
Fernández-Tabales, A. \& Cruz, E. (2013). Análisis territorial del crecimiento y la crisis del sector de la construcción en España y la Comunidad Autónoma de Andalucía. EURE, 39(116), 5-37. https://www.eure.cl/index.php/eure/article/viewFile/242/560

Gaja i Díaz, F. (2008). El "tsunami urbanizador" en el litoral mediterráneo: el ciclo de hiperproducción inmobiliaria 1996-2006. Scripta Nova, Revista Electrónica de Geografía $y$ Ciencias Sociales, 12(270). http://www.ub.edu/geocrit/sn/sn-270/sn-270-66.htm

García, R (2008). Tensiones socio-ambientales entre una ruralidad productiva y otra residencial en la Región de Murcia. En J. M. Gómez \& R. Martínez (eds.), Los espacios rurales españoles en el nuevo siglo (pp. 279-294). Murcia: EDITUM (Ediciones de la Universidad de Murcia).

Harvey, D. (1980). A justiça social e a cidade. San Pablo: Hucitec.

Harvey, D. (1993). A condição pós-moderna. San Pablo: Loyola.

Harvey, D. (2005). A produção capitalista do espaço. San Pablo: Annablume.

Harvey, D. (2011). O enigma do capital: e as crises do capitalismo. San Pablo: Boitempo.

Huete, R. (2008). Tendencias del turismo residencial: el caso del Mediterráneo español. El periplo sustentable, (14), 65-87. https://rperiplo.uaemex.mx/article/view/5052/3642

Huete, R. \& Mantecón, A. (2011). Más allá del turismo: movilidad residencial europea y nuevos núcleos urbanos. Boletín de la Asociación de Geógrafos Españoles, (56), 111-128. https://www.age-geografia.es/ojs/index.php/bage/article/view/1346/1269

Huete, R., Mantecón, A. \& Estévez, J. (2013). Challenges in lifestyle migration research: Reflections and findings about the Spanish crisis. Journal Mobilities, 8(3), 331-348. https://doi.org/10.1080/17450101.2013.814236

Janoschka, M. \& Haas, H. (2014). Contested spatialities, lifestyle migration and residential tourism. Nueva York: Routledge.

Jurdao, F. (1979). España en venta: compra de suelo por extranjeros y colonización de campesinos en la Costa del Sol. Madrid: Endymion.

Lefebvre, H. (1972). La revolución urbana. Madrid: Alianza Editorial.

Mantecón, A., Huete, R. \& Mazón, T. (2009). Las urbanizaciones “europeas”. Una investigación sobre las nuevas sociedades duales en el mediterráneo. Scripta Nova. Revista Electrónica de Geografia y Ciencias Sociales, 13(301). http://www.ub.edu/geocrit/sn/sn-301.htm

Martínez-Medina, A. (2016). Arquitectura del boom turístico (1953-1979). Canelobre (Revista del Instituto Alicantino de Cultura "Juan Gil-Albert"), (66), 166-185. http://rua. ua.es/dspace/handle/10045/60032

Mateu i Lladó, J. (2003). Turismo residencial y dispersión urbana en Mallorca (Illes Balears): un ensayo metodológico en el municipio de Pollença. Estudios Turísticos, (155-156), 197-218.http://estadisticas.tourspain.es/img-iet/Revistas/RET-155-156-2003pag197-218-90156.pdf

Mazón, T. (2016). Orígenes y desarrollo turístico en Alicante: del veraneo al turismo de masas. Canelobre (Revista del Instituto Alicantino de Cultura "Juan Gil-Albert"), (66), 38-51. https://rua.ua.es/dspace/bitstream/10045/57366/1/2016_Mazon_Canelobre.pdf

Moreno, A. (2007). Historia del turismo en España en el siglo XX. Madrid: Síntesis.

Mullins, P. (1991). Tourism urbanization. International Journal of Urban Regional Research, 15(3), 326-342. https://doi.org/10.1111/j.1468-2427.1991.tb00642.x

Nunes, M. R. (2014). Investimentos internacionais e o turismo em Tibau do Sul/RN. (Tesis de maestría inédita). Universidade Federal do Rio Grande do Norte, Natal. 
Paiva, R. A. \& Vargas, H. C. (2013). Sobre a relação turismo e urbanização. Pós, 20(33). 126145. https://doi.org/10.11606/issn.2317-2762.v20i33p126-145

Pinheiro, M. V. (2011). Reprodução do capital e metamorfoses espaciais. Um estudo da verticalização de Ponta Negra - Natal/RN. (Tesis de maestría inédita). Universidade Federal do Rio Grande do Norte, Natal.

Ponce, M. D. \& Espejo, C. (2009). La percepción de los resorts en la Región de Murcia a través de la prensa. En T. Mazón, R. Huete \& A. Mantecón (eds.), Turismo, urbanización y estilos de vida. Las nuevas formas de movilidad residencial (pp. 439-450). Barcelona: Icaria. https://bit.ly/2Yh1oSr

Pontes, M. A. (2005). Espaço, politicas de turismo e competitividade. Natal, Brasil: EDUfRN (Editora da Universidade Federal do Rio Grande do Norte).

Pontes, M. A. (2007). Tendências atuais do turismo potiguar: a internacionalização e a interiorização. En M.A. Pontes, E. Nunes, E. Carvalho \& E. M. Furtado (eds.), Dinâmica e gestão do território potiguar (pp. 215-231). Natal: EDUFRN (Editora da Universidade Federal do Rio Grande do Norte).

Pontes, M. A. \& Lima, R. M. (2011). O perfil do consumidor estrangeiro de segunda residência na regiáo metropolitana de Natal. En E. Kyoko \& de S. Araujo (eds.), Turismo: conhecimento, tecnologias e inovação. Camboriú, Brasil: Aleph.

Pontes, M. A. \& Silva, K. (2012). Origem e evoluçáo das segundas residências no Polo Costa das Dunas. En M. A. Pontes (ed.), Segunda residência, lazer e turismo (pp. 95-126). Natal, Brasil: EDUfrn (Editora da Universidade Federal do Rio Grande do Norte).

Pontes, M. A., Santos, A. P. \& Nunes, M. R. (2016). Reestruturaçáo produtiva, turismo e investimentos internacionais no litoral potiguar. Formação, 1(23), 158-176. http:// revista.fct.unesp.br/index.php/formacao/article/view/3283/3176

Rejowski, M. (2002). Turismo no percurso do tempo. São Paulo: Aleph.

Salvá, P. A. (1998). Los modelos de desarrollo turístico en el Mediterráneo. Cuadernos de Turismo, (2) 7-24. https://revistas.um.es/turismo/article/view/23401/22671

Santos, A. P. (2015). Investimentos internacionais e a valorização imobiliária dos municípios de Maxaranguape e Rio do Fogo. (Tesis de maestría inédita). Universidade Federal do Rio Grande do Norte, Natal.

Serrano Martínez, J. M., Espejo Marín, C. \& García Marín, R. (2016). Accesibilidad aérea en la Región de Murcia: una encrucijada compleja desde una perspectiva turística. Papers de Turisme, (59), 62-85. http://www.papersdeturisme.gva.es/ojs/index.php/Papers/ article/view/469

Silva, M. G. (2004). Cidades turísticas. Identidades e cenários de lazer. São Paulo: Aleph.

Silveira M. A. T. \& Rodrigues, A. B. (2015). Touristic urbanization in Brazil: A Focus on Florianópolis - Santa Catarina. Vi@ Tourism Review, 1(7), 1-14. https://journals. openedition.org/viatourism/625

Silva, A. F. (2010). O litoral e a metrópole. Dinâmica imobiliária, turismo e expansão urbana na Região Metropolitana de Natal-RN. Tesis de doctorado en Conforto no Ambiente Construído; Forma Urbana e Habitação; Universidade Federal do Rio Grande do Norte, Natal. https://repositorio.ufrn.br/jspui/handle/123456789/12292 
Silva, A. F. \& Ferreira, Â. (2012). Imobiliário-turístico no litoral nordestino: investimentos estrangeiros e impactos locais nas praias potiguaras. En M. A. Pontes (ed.), Segunda residência, lazer e turismo (pp. 127-156). Natal, Brasil: EDUfRN (Editora da Universidade Federal do Rio Grande do Norte).

Soares, J. C., Ivars, J. A. \& Gândara, J. M. (2015). La evolución de destinos litorales consolidados. Análisis comparado de Balneario Camboriú (Brasil) y Benidorm (España). Anales de Geografía de la Universidad Complutense, 35(2), 143-166. https:// revistas.ucm.es/index.php/AGUC/article/view/50118/46580

Spósito, M. E. (2009). Urbanização difusa e cidades dispersas: perspectivas espaço-temporais contemporâneas. En N. Reis (ed.), Sobre dispersão urbana (pp. 38-54). San Pablo: Via das Artes.

Vera, F. \& Espejo, C. (2006). El papel de los instrumentos de planificación en las dinámicas productivas y territoriales. En J. Romero \& J. Farinòs (eds.), Gobernanza territorial en España. Claroscuros de un proceso a partir del estudio de casos (pp. 61-79). Valencia: Servicio de Publicaciones de la Universidad de Valencia. 